\title{
The Impact of Social-Economic Factors on Students' English Language Performance in EFL Classrooms in Dubai
}

\author{
Walid Salameh ${ }^{1}$ \& A. A. Sathakathulla ${ }^{2}$ \\ ${ }^{1}$ British University in Dubai, UAE \\ ${ }^{2}$ Federal Electricity and Water Authority, Dubai, UAE \\ Correspondence: A. A. Sathakathulla, Federal Electricity and Water Authority, Dubai, UAE.
}

Received: December 24, 2017 Accepted: October 22, $2018 \quad$ Online Published: November 28, 2018

doi: $10.5539 /$ ells.v8n4p110

URL: https://doi.org/10.5539/ells.v8n4p110

\begin{abstract}
This paper deals with assessing the impact of socio-economic factors on students' English language performance in EFL classrooms in Dubai public secondary schools by exploiting a mixed methods research. By doing in depth case study analysis and by using some statistical tools followed by interviews the assessment on Students' being studied. The impact of this study reveals that the factors involved by students' points as well by the parent side being considered. The various factors by both sides have an impact on the learning attitude and performance in EFL class rooms which affects in class room phenomenon. The significance of this study using correlation analysis being carried out and the impact is registered accordingly for future analysis.
\end{abstract}

Keywords: EFL, socio- economic factors, English language performance

\section{Introduction}

In the United Arab Emirates, English Language is a major factor affecting students' admission to and performance at universities as well as in the workplace where fluency in English language has become an indispensable requirement. As a rule, all universities working in the UAE require that all students have either a TOEFL or an IELTS certificate as a pre-requisite for any course to be taken. The importance of English Language in the United Arab Emirates, constantly highlights the importance of analyzing the factors affecting that performance. As a matter of fact, socio-economic factors can potentially have a formative effect on students' performance.

The basic aim of this study is to find out the extent to which the socio-economic status of parents is related to students' English language performance at the selected six public secondary schools in Dubai. This study planned to pose with the questions that.

- In what way do the factors of age and gender affect the respondents' attitudes?

- To what extent does parents' educational level influence students' English language performance in the EFL classroom in the selected schools?

- Does parents' financial status affect students' English language performance in the EFL classroom in the selected schools?

- What is the relationship between parents' occupation and the students' English language performance in the EFL classroom in the selected schools?

To pursue this study in hypothetical way, we observe that

H0: There is no relation between age and the impact of social and economic factors on students' English language performance.

H1: There is a relation between age and the impact of social and economic factors on students' English language performance.

It is hoped that the information in this research can help different stakeholders, including educational planners, school administrators, parents, teachers and further researchers in understanding the social and economic status of parents in relation to students' performance 


\section{Literature Review}

There are three determining angles that need to be considered in this study (Blythe, 2010). Firstly, is the analysis of English Language performance in association with the personal educational level of the parents. According to Grissmer (2013), parents' educational level is the most important factor affecting students' performance. This was also emphasized by Taiwo (2009) who believed that the educational background of the parents' is of great importance as it helps parents' to be second teachers for their child and even guide the child and council him/her on the best way to perform well in education and provide the vital materials he/she needs.

Secondly is the financial status of parents and its effects on the English Language performance of students. According to Odebumni (2008) and Egbule (2010), finance is the avenue through which the students' bills are paid. If there is a shortage in the student's finances, this will probably affect his/her academic performance adversely, while if on the other hand the financial needs of the students are met adequately, probably their academic performance may be enhanced (Odebumni, 2008; Egbule, 2010).

Thirdly is the occupation of the parents. A number of studies have investigated the relation between parents' occupational status and students' performance and have come to find that the students with parents in professional and white-collar occupations were found to be about a third more likely to join university than young people with parents in blue-collar occupations (Long et al., 1999, p. 61). Similarly, an earlier study conducted by William et al. (1993) has shown that higher education participation rates were highest for students whose parents were from professional backgrounds as opposed to lower status occupational groups.

\subsection{The Relationship between Socio-Economic Factors and the Performance of English Language Learners}

Performance is chiefly a yield of mental and economic satisfaction with a particular thing. If a person is mentally and socially satisfied, then positive result will reflect on his/her performance in almost everything (Nigel \& William, 2005; Hill et al., 2004). This amounts to saying, in the immediate context of our preoccupation here, that there is a strong relationship between economic and social factors and ad hoc performance of English Language learner (Nigel \& William, 2005). The socio-economic standing (SES) of a student is namely evaluated by merging parents' educational echelon, occupational standing, and income level (Jeynes, 2002). Studies have habitually shown that SES influences student results (Majoribanks, 1996; Jeynes, 2002; Eamon, 2005). Students who have a low SES attain less test grades and tend to be more prone to withdrawing from school. Low SES students have been found to achieve grades about $10 \%$ lower on national assessment programs than higher SES learners (Seyfried, 1998). Early research has illustrated that children who only have one parent, do not execute as sufficiently as those who have both parents around, for students with a single parent, generate less income than those with both parents (Majoribanks, 1996).

The biggest aspect that plays a vital role in directing the performance of English Language learner is mental satisfaction (Richard, 1995; Hill et al., 2004). Economic prosperity or economic flow will ultimately enhance the performance level of a student towards learning, but the case is not always right, because sometimes the flow of economy makes a person rude and proud.

Apart from economic factors, there are social factors as well which play an important role in directing the performance of the students who wish to take English language classes. Social Factors, like buying behaviour, are important to discuss because the association of fees is very high with English Language learning programs (Richard, 2009). A competitive world has increased the demand of customer value for organization and that is the main reason why customers have been referred to as intangible assets for a firm (Khodadady \& Zabihi, 2011). The value of the customer depends on the product's perceived performance in delivering value relative to buyer's expectations (Borodovsky \& Gogarten, 2010). Social Factors like customer behaviour or customer satisfaction increased the demand of a customer in front of the seller or in front of an organization (Eng, 2009). The students who have a strong economic background are treated in a somewhat different manner from those who have low economic profile (Richard, 2009). According to the specification of this study, there are three different contexts in which this relationship will be analyzed. The first context will analyze the performance in English Language in relation to the educational level of the parents.

\section{Materials and Methods}

The method exploited throughout this study is a mixed-method approach. It comprises philosophical assumptions that conduct the course of the compilation and breakdown of data, and the blend of qualitative and quantitative tactics in numerous stages during the research development. The dependent variables are the students' English language scores (which were obtained from the respondents' English language instructors), age, gender, class and the independent variables are parents' education, parents' occupation and parents' financial 
status.

\subsection{Research Population}

The population of the study was six secondary schools in Dubai, three secondary schools for boys with a population of 600 students, and three secondary schools for girls with a population of 600 students. The total population in this study was 1200 students from both male and female secondary schools. Those who participated in this study were 210 male students and 174 female students who were selected randomly. The participants in the study were from grades 10,11, and 12. The ages of the participants from the schools were 15, 16, and 17. As mentioned, the participants were selected randomly with different levels in English language and belong to different socio-economic status to see to what extent the social and economic factors affect students' English language performance, besides; six English language teachers (3 male English language teachers and 3 female English language teachers) were interviewed. Two of the interviewed English language teachers hold an MA degree in English language and the other four English language teachers hold BA degree in English language in a way that an English teacher from each secondary school was interviewed. Furthermore; two principals from the selected four schools (one male principal and one female principal) were interviewed as well, by the researcher to make a total 392 participants in this study.

\subsection{Sample Size}

The two questionnaires which were first used by Sir Francis Galton (1874) for the sake of pioneering the views of others were distributed over the students from the six Public secondary schools in Dubai. The secondary level was selected due to the fact that it is the final stage in the school life after which students are supposed to join a university of their choice after passing one of the proficiency tests (TOEFL or IELTS) that measures their level of English. As mentioned above, the selection of students in this study was done randomly, but the researcher took into consideration to have students from grade ten and students from grade eleven and others from grade twelve. The number of the participants from each class is not equal in which 164 students were from grade ten, 129 students from grade eleven and 91 students from grade twelve from both male and female students, therefore, and this sample suited the purpose of this study on the students who attend the secondary cycle. The levels of the students' English proficiency were scattered away from the average grade band, this was found through examining the participant's performance level, which were provided by their instructor.

The selected six English language teachers from the six secondary schools and the two head teachers in Dubai were interviewed to further investigate if there is an impact of socioeconomic factors on students' English language performance or not.

\subsection{Research Instruments}

The two instruments which were exploited in this study were questionnaires and interviews regarding the social and economic factors affecting students' English language performance. These two instruments are attached in (Appendix A and B)

\subsection{Validity and Reliability of the Instruments}

In order to establish the validity of the instruments, the instruments represented in the two questionnaires and the teachers' interviews questions were piloted to get the approval of proceeding with the study on the basis of such instruments. The questions were reviewed, thus allowing for amendments to be done on the questionnaires' questions and the interview questions. In order to determine reliability of the questionnaires, the SPSS Cronbach Alpha which was first used by Lee Cronbach was used to calculate the correlation between the two factors (the social and economic factors affecting students' English language performance). The correlation is measured by person's correlation coefficient $(r=0.76)$. By calculating according to the data given, it should be noted that " $r$ " is a value that falls between -1 and 1 .

\subsection{Analysis of Data}

One key instrument utilized in this study is statistical analysis, descriptive and inferential are used. Statistical software is employed to analyze the data collected. To start with, personal variables represented in class, gender, age and grades have been analyzed first to see the class of the respondents, their gender, age and grades in English language. . Following are the analyzed questionnaires and the interviews. 


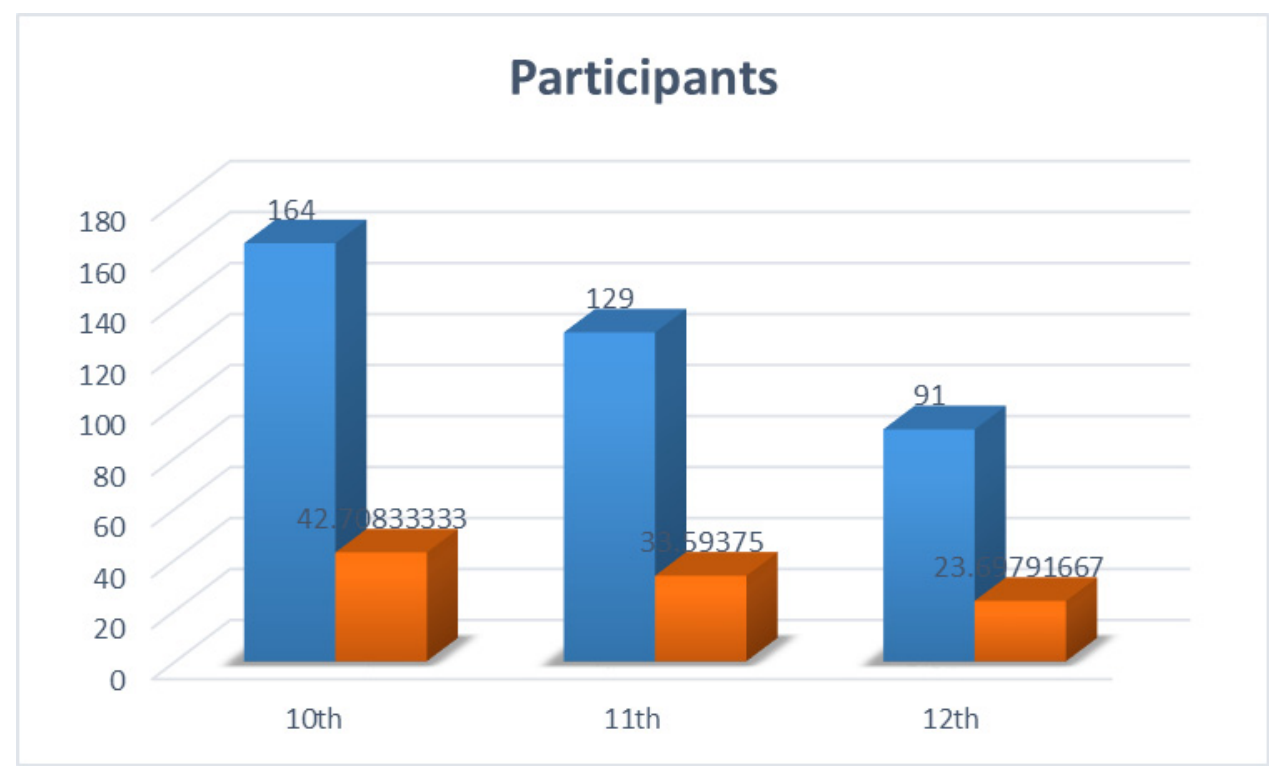

Figure 1. The number of respondents who were selected to answer the questionnaire

Figure 1 shows the number/percentage of the respondents from each class which includes male and female students $(10,11,12)$ who were selected to answer the questionnaires.

\section{Questionnaires and Results Analysis}

The format of a typical five-level Likert scale is used for this research ("Agree" "Strongly agree" "Neutral" "Disagree" "Strongly disagree"). This type of questionnaires was first initiated by Sir Francis Galton (1874). The two questionnaires consisted of twenty questions and were designed for this specific study. One questionnaire was on social factors affecting students' English language performance in EFL classrooms. The questions were separated into two sections, ten of which revolved around the importance of English language, the importance of having parents fluent in English. This added to questions on the use of English, whether in public places or at home or with classmates to improve the students' performance of English language. The other was on economic factors affecting students' English language performance which was of ten sentences that revolved around the parents' education, parents' occupation and parents' financial status.

\subsection{Interview Analysis}

A randomly selected group of six English language teachers and two principals were interviewed and asked about their opinions on the relationship between students' performance in learning the English language and their parents' social and economic status. Teachers and principals used their experience and knowledge of students, their parents, and their performance to assess the relationship. The interviewees are three male and three female teachers of the English language, a male principal, and a female principal. The male teachers and principal answered the questions in relation to male students, and similarly for female teachers and principal. This section presents the questions along with the general opinions of the teachers and the principals. The Principals were only asked questions 2,4 , and 6 .

The teachers confirmed the parents' key role on their children's performance in school, in general, and in learning the English language, specifically. Those teachers identified the parents' recognition of the importance of education as the determining factor of children's performance, particularly during the onset of their schooling years. Parents who recognize education as a goal for the children emphasize this during the children's early years and encourage them to develop cognitive and language skills during their development. During the children's later years, parental involvement with teachers is as important to sustain the students' performance. Only one teacher expressed a disagreeing opinion, where she believed that parents do not necessarily have an impact on their children or their performance. She cited cases where students with illiterate parents achieved results similar to those with highly educated parents. 


\subsection{Results Analysis}

Table 1. Analysis of student's responses who were selected to answer the questionnaire

\begin{tabular}{lllllll}
\hline \multirow{2}{*}{ Class } & Response & & & & & \\
& Strongly Agree & Agree & Neutral & Disagree & Strongly Disagree & Total \\
\hline 10th & 75 & 56 & 22 & 0 & 11 & 164 \\
11 th & 72 & 21 & 17 & 11 & 8 & 129 \\
12 th & 60 & 19 & 12 & 0 & 0 & 91 \\
Total & 207 & 96 & 51 & 11 & 19 & 384 \\
\hline
\end{tabular}

\begin{tabular}{llllll}
\hline ANOVA table & \multicolumn{1}{l}{ MS } & $F$ & p-value \\
\hline Source & $S S$ & $d f$ & 266.600 & 0.35 & .7133 \\
Treatment & 533.20 & 2 & 767.200 & & \\
Error & $9,206.40$ & 12 & & & \\
Total & $9,739.60$ & 14 & & & \\
\hline
\end{tabular}
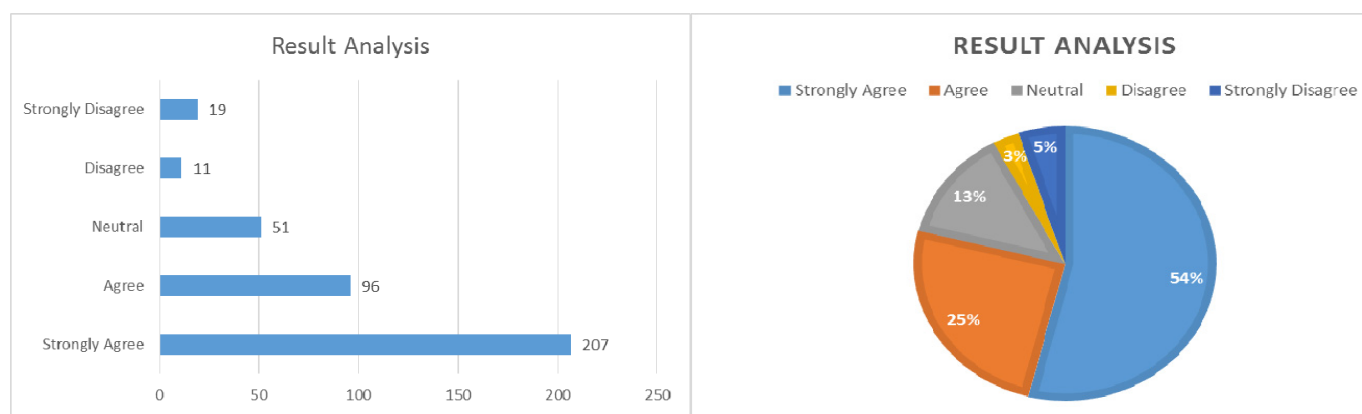

Figure 2. Analysis of student's responses who were selected to answer the questionnaire

The above two charts are claiming the number of responses for each category of five Likert scale measures and the respective percentage of responses. It clearly depicts that the maximum number of responses comes with agree and strongly agree as 303 about $79 \%$. It evidently supports that Cronbach alpha value also 0.76 accepts the reliability of data as well as the strong support of the hypothesis that the impact is significant. Further, while analyzing the variance using ANOVA, it reveals that $\mathrm{F}=0.35$ and $\mathrm{P}$ value is 0.7133 which highly agrees with the acceptance of hypothesis

\section{Discussion and Recommendations}

As previously mentioned regarding the impact of socio-economic factors on students' English language performance, statistics are employed in this study to draw conclusions. In the following sections, inferential statistics are used to generalize the sample conclusions about the population. Particularly, the chi-squared distribution is used to test the hypotheses for class, gender, age, and grade. Correlations with a $95 \%$ confidence interval are drawn between students' performance in learning English language and those factors, which means that there is an impact of these factors on students' performance.

\subsection{Hypothesis Testing}

Null Hypothesis $\left(\mathrm{H}_{\mathrm{o}}\right)$ : There is no relation between class and the impact of socio-economic factors on students' English language performance.

Alternative hypothesis $\left(\mathrm{H}_{1}\right)$ : There is a significant difference of relation between class and the impact of socio-economic factors on students' English language performance.

The results of the questionnaire show that there are significant relationships between class level and the views that speaking English at home enhances the learning of language. In other words, the older the students, as reflected by the results, the more aware that practice can enhance their learning. This can be explained by the fact that the maturity of the students plays a significant role in their understanding of the importance of practicing English at home and elsewhere so as to improve their English learning performance in classroom. In psychological terms, age has something to do with the feeling of responsibility among teenagers: the older they 
grow, the more responsible they feel. This seems to apply perfectly to the older students participating in the questionnaire: they have demonstrated more understanding and awareness of the necessity of practicing English outside the school context.

The other significant relationship is between class level and the views that non-curricular activities enhance classroom performance. Here, the results of the questionnaire show that both the younger and the older students converge on the impact of non-curricular activities on classroom performance. However, they disagree on the kind of non-curricular activities preferred. While the older students improve their understanding of English language through practicing it with their family and friends, the younger students feel that they benefit more from hearing or reading the language.

Taken as a whole, there are significant relationships between class level and the views that wealth and self-confidence are correlated, that a well-provided home environment affects class performance, and that financial wealth helps students' English language performance.

The test shows a relationship at a significance of $\alpha=0.05$ between grade and several socio-economic factors.

Similarly, relationships between grade and the impact of parents' education on students' English language performance were observed at a significance level of $\alpha=0.05$. Specifically, grade was strongly related to the impact of parents' qualifications on English learning and the effect of the parents' education on students' English language performance.

The findings that are presented here support the existing literature review. Steven (1999) and Khodadadi \& Zabihi (2011) have found a correlation between parents' educational level and the performance of their children. The impact of parents' education is emphasized by Steven (2002) who stated that psychologists have shown that parents who are good in education ultimately become the role models of their children and thus have a positive impact over the thinking and performance of their children. Moreover, the relationship between grade and the impact of parents' education on students' English language performance is clear in the work of Nannyonjo (2007) who found out that pupils with parents who did not finish primary or just primary, performed worse than pupils with parents who finished university degree, which means that the education of parents has a veritable impact on the performance of the children. Parents' education was also highlighted by Taiwo who believed that educated parents can be second teachers, can even guide and counsel the child on the best way to perform well in education and can provide the necessary materials he/she needs. Besides, Musgrave (2000) said that a child who comes from an educated family would like to imitate his father and mother and, consequently, work actively in his/her studies.

In the light of what have been mentioned above, we can say that grade is strongly related to parents' education as shown in the analyzed sentence in chapter 4 in which the respondents perfectly agreed with the statement. This is reinforced by the literature review that emphasizes this issue.

\subsection{Limitations of the Study}

This study has its limitations. Firstly, the students' parents were not interviewed, but information about their education and sources of family income were provided by pupils through their responses to the questions in the questionnaires. The researcher did not have full control over the honesty of the respondents, their motivation and their personal biases. He therefore tried, with the help of his assistants, to encourage them to be objective when answering the questionnaires.

Additionally, the sample of the study is restricted to six secondary schools, three boys' schools and three girls' schools. The number of the participants was 384 from the six secondary schools, i.e. 64 participants from each school on average.

\section{Conclusion}

The purpose of this study was to assess the impact of socio-economic factors on students' English language performance in EFL classrooms in Dubai public secondary schools. The research has tried to identify parents' education, parents' financial status, and parents' occupation to see whether these factors are significantly affecting students' English language performance at secondary level or not. This study proved that there is an impact of such factors on students' English language performance. The three angles we explored were: parents' education, parents' financial status, and parents' occupation. It is expected that the findings of this study will pave the way for other researchers to undertake further investigations and find solutions on the basis of the discerned results.

Finally, it should be accentuated that learners who belong to wealthier socio-economic and cultural family 
environment are apparently more prone to gain higher echelons of success in English. However, the lack of comparable privilege in relation to parents' culture, namely the mothers' education, will not help to accomplish an individual's complete prospective. Nonetheless, it is central to examine the habits by which parents, as the adolescent's primary educators, can be directed to cultivate the person's foreign language progress via the integration of literacy techniques involving both home and school.

\section{References}

Ackerman, R. (2002). Perfect research. New York: Prentice Hall Publications.

Blythe, J. (2010). Economic and social analysis. London: John Wiley \& Sons Professional Publications.

Borodovsky, M., \& Gogarten, P. (2010). Economic and Social Analysis. Oxford Publications.

Egbule. (2010). Practical guide to a successful project or thesis in writing and defence. Owerri: Whyte and Whyte Publishers.

Grissmer, R. H. (2013). Beyond helping with homework: parents and children doing mathematics at home. Teaching Children Mathematics, 14, 120-131.

Hill, N. E., Castelino, O. R., Lansford, J. E., Nowlin, E., Dodge, P., Bates, K. A., \& Pettit, G. S. (2004). Parents academic involvement as related to school behaviour, achievement and aspirations: demographic variations $\begin{array}{lllll}\text { across adolescence. } & \text { Child }\end{array}$ https://doi.org/10.1111/j.1467-8624.2004.00753.x

Jeynes, W. H. (2002). Examining the effects of parental absence on the academic achievement of adolescents the challenge of controlling for family income. Journal of Family and Economic Issues, 23(2), 189-210. https://doi.org/10.1023/A:1015790701554

Khodadady, E., \& Zabihi, R. (2011). School performance, cultural, social and personality factors and their relationships with majoring in foreign and first languages. English Language Teaching, 4(3), 63-73. https://doi.org/10.5539/elt.v4n3p63

Khodadady, E., \& Zabihi, R. (2011). Social and cultural capital: underlying factors and their relationship with the school achievement of Iranian University students. International Education Studies, 4(2), 63-71. https://doi.org/10.5539/ies.v4n2p63

Long. M., Carpenter, P., \& Hayden, M. (1999). Participation in education and training. LSAY research report No. 13, Australian Council for Educational Research, September.

Marjoribanks, K. (1996). Family learning environments and students' outcomes: a review. Journal of Comparative Family Studies, 27(2), 373-394.

Musgrave, C. B. (2000). Environmental Factors Affecting Attitude towards Science and Mathematics. Journal of Educational Psychology, 91(1), 382-394.

Nannyonjo, H. (2007). Education inputs in Uganda: An analysis of factors influencing learning achievement in grade six. World Bank Policy Research Paper No. 98. Washington, DC: World Bank. https://doi.org/10.1596/978-0-8213-7056-8

Nigel, P., \& William, G. (2005). Economic and social analysis. Marketing Intelligence \& Planning, 7(5/6), 5-7.

Odebunmi, A. (2008). The effect of home background on students' academic performance. Nigeria Journal of Educational Psychology, 6(1), 8-9.

Richard, D. (2009). Economic and social analysis (2nd ed.). New York: Prentice Hall Publication.

Seyfried, S. F. (1998). Academic achievement of African American preadolescents: the influence of teacher perceptions. American Journal of Community Psychology, 381. https://doi.org/10.1023/A:1022107120472

Steven, P. (1999). Mar economic and social analysis (Vol. 2). New York: McGraw Hill Publications.

Steven, P. (2002). Economic and social analysis (Vol. 3). New York: McGraw Hill Publications.

Taiwo, H. G. (2009). Family environment and educational attainment of some school children in Western Nigeria. Journal of the Science Teachers Association of Nigeria, 46(2), 107-116.

Williams, T., Long, M., Carpenter, P., \& Hayden, M. (1993). Entering higher education in the 1980s, report submitted for the evaluations and investigations program. Department of Education, Employment and Training, July 14. 


\section{Appendix A}

Two Questionnaires about the Impact of Social and Economic Factors on Students' English Language Performance in EFL Classrooms

Gender:

Grade:

- The following is a questionnaire on 'the impact of social and economic factors on student's English language performance'

- $\quad$ Please indicate your level of agreement with each of the following statements by putting tick mark ( $\checkmark$ ) appropriately:

- You are kindly requested to provide accurate response for all questions.

\section{1) Social Factors}

1- The English language is an essential language for our social life.

2- Being the primary language in our world, knowing English is important.

3- As a medium of communication in all aspects, the English language is helpful for your future occupation.

4- Having a parent with qualifications may positively serve the learning of the English language.

5- Having one or both of your parents fluent in the English language, may help the process of acquiring the learning English.

6- Practicing English at home with your parents, will urge you to enhance your performance in class.

7- Practicing English with your classmates in your free time helps in your performance in class.

8- Being able to communicate in public places gives you self confidence that will be projected in your classroom.

9- Reading books with your friends or watching television with your parents encourages your improvement in class.

10- Deriving from a poorly educated family, may or may not affect your English performance in class.

\section{2) Economic Factors}

1- Being economically wealthy, gives you self confidence, and helps in your performance in class.

2- More income gives you the opportunity to fulfil more than your basic needs.

3- For better communication in business, the English language is helpful.

4- A well-provided home environment is helpful for a better performance in the class communication process.

5- The nature of your parents' occupation may have an effect on English learning process.

6- Both of your parents being employed in a decent job may facilitate and urge your performance in English better.

7- Being of a wealthy background, positively and critically establishes an anxiety and trouble-free environment that helps in your English language performance.

8- Coming from a wealthy family, allows you to invest more energy into an adequate performance in English.

9- The English fluency of your mother, is more likely to assist in your English language learning.

10- There is no relationship between the parents' Economic status and the students' achievements.

* Do you think that there is an effect of your parents' social and economic status on your performance at English language? How? Why?

Thank you for your cooperation and time spent in completing this questionnaire. 


\section{Appendix B}

\section{Interview Questions}

1- Do parents have a clear impact on their children's performance? How?

2- What is the relationship between parents' education and students' performance?

3- Which is more effective, parents' education or parents' income on students' English language performance?

4- To what extent are students motivated to increase their achievement by their parents' education?

5- To what extent are students motivated to increase their achievement by their parents' income?

6- Do you think that there is a relationship between parents' occupation and students' performance? How?

\section{Copyrights}

Copyright for this article is retained by the author, with first publication rights granted to the journal.

This is an open-access article distributed under the terms and conditions of the Creative Commons Attribution license (http://creativecommons.org/licenses/by/4.0/). 